\title{
Review \\ Neuroimaging in Psychiatric Pharmacogenetics Research: The Promise and Pitfalls
}

\author{
Mary Falcone ${ }^{1,2}$, Ryan M Smith ${ }^{3}$, Meghan J Chenoweth ${ }^{4}$, Abesh Kumar Bhattacharjee ${ }^{5}$, John R Kelsoe , $^{5}$ \\ Rachel F Tyndale ${ }^{4}$ and Caryn Lerman*,2 on behalf of the Pharmacogenomics Research Network Central \\ Nervous System Working Group
}

'Department of Pharmacology, University of Pennsylvania, Philadelphia, PA, USA; ${ }^{2}$ Center for Interdisciplinary Research on Nicotine Addiction, Department of Psychiatry, University of Pennsylvania, Philadelphia, PA, USA; ${ }^{3}$ Department of Pharmacology, Program in Pharmacogenomics, Ohio State University, Columbus, OH, USA; ${ }^{4}$ Campbell Family Mental Health Research Institute, Centre for Addiction and Mental Health, Department of Psychiatry, Pharmacology and Toxicology, University of Toronto, Toronto, Ontario, Canada; ${ }^{5}$ Department of Psychiatry, University of California, San Diego, La Jolla, CA, USA

\begin{abstract}
The integration of research on neuroimaging and pharmacogenetics holds promise for improving treatment for neuropsychiatric conditions. Neuroimaging may provide a more sensitive early measure of treatment response in genetically defined patient groups, and could facilitate development of novel therapies based on an improved understanding of pathogenic mechanisms underlying pharmacogenetic associations. This review summarizes progress in efforts to incorporate neuroimaging into genetics and treatment research on major psychiatric disorders, such as schizophrenia, major depressive disorder, bipolar disorder, attention-deficit/hyperactivity disorder, and addiction. Methodological challenges include: performing genetic analyses in small study populations used in imaging studies; inclusion of patients with psychiatric comorbidities; and the extensive variability across studies in neuroimaging protocols, neurobehavioral task probes, and analytic strategies. Moreover, few studies use pharmacogenetic designs that permit testing of genotype $\times$ drug effects. As a result of these limitations, few findings have been fully replicated. Future studies that pre-screen participants for genetic variants selected a priori based on drug metabolism and targets have the greatest potential to advance the science and practice of psychiatric treatment. Neuropsychopharmacology (2013) 38, 2327-2337; doi: I0.1038/npp.20।3.152; published online 17 July 2013
\end{abstract}

Keywords: neuroimaging; pharmacogenetics; psychiatry; treatment

\section{INTRODUCTION}

Approximately $25 \%$ of the population is afflicted by one or more psychiatric disorders (Kessler et al, 2005). Twin studies reveal a substantial heritability for psychiatric disorders, including schizophrenia and bipolar disorder (BD), major depression, and substance use disorders including nicotine dependence (McGuffin et al, 2003; Goldman et al, 2005; van Belzen and Heutink, 2006). Although pharmacotherapy represents the foundation of psychiatric treatment, most patients do not achieve a sufficient therapeutic response. To improve treatment outcomes, genetic variants that code for drug-metabolizing enzymes and pharmacodynamic targets are being examined to identify individuals most likely to benefit from alternate therapies and those at risk for adverse drug reactions (Malhotra et al, 2012). Despite some progress, there are a

*Correspondence: Dr C Lerman, Mary W Calkins Professor of Psychiatry, Center for Interdisciplinary Research on Nicotine Addiction, Department of Psychiatry, University of Pennsylvania, 3535 Market Street, Suite 4100, Philadelphia, PA 19104, USA, Tel: + I 215 746-7I4I; Fax: + I 215 746-7|40; E-mail: clerman@upenn.edu Received I5 January 2013; revised 10 June 2013; accepted 10 June 2013; accepted article preview online 24 June 2013 limited number of actionable findings, due in part to the low penetrance of implicated genes and a failure to capture the complexity in pathophysiological phenotypes that give rise to variable treatment outcomes.

Moving beyond simple classifications of treatment responders and nonresponders, genetic variability can be studied in the context of intermediate phenotypes related to treatment effects on brain structure, neural circuitry, and neurochemical processes (Meyer-Lindenberg and Weinberger, 2006). There are a variety of neuroimaging approaches that have substantial potential utility in this regard, including: blood-oxygen-level-dependent (BOLD) functional magnetic resonance imaging (fMRI) to examine neural activity associated with treatment targets such as attention, working memory, reward-related responding, emotional processing, and in the case of addiction, reactivity to drug-related cues; BOLD signal at rest to characterize spontaneous fluctuations of connectivity within and between neural circuits; and positron emission tomography (PET) to estimate receptor availability and neurotransmitter levels in the brain. Although the imaging genetics approach has been used to study underlying pathophysiological processes in psychiatric conditions (Tost et al, 2012), few studies have combined both genetic 
and imaging approaches to study effects of psychiatric treatment. The goal of this paper is to outline promising avenues for, and the challenges of, incorporating neuroimaging phenotypes into psychiatric pharmacogenetics research.

\section{STATE OF THE SCIENCE}

We reviewed existing literature incorporating neuroimaging phenotypes into work on genetic influences on treatment response. For each imaging phenotype, we selected studies that have the following characteristics: (a) human psychiatric patient population or healthy controls exposed to relevant drug treatment or drugs of abuse, with assessment of drug response; (b) neuroimaging assessment; and (c) genetic analysis. Studies meeting these criteria are listed by imaging phenotype in Table 1 and discussed below.

\section{Working Memory Assessed with fMRI}

Deficits in working memory have a central role in both psychiatric illness and addiction, based on its centrality to cognitive control and goal-directed behavior (Millan et al, 2012; Ashare et al, 2013). Several studies have examined genes involved in dopamine regulation for a role in working memory-related brain activity and treatment response; these studies suggest that alleles associated with reduced dopaminergic tone may enhance the cognitive effects of drug treatment. The widely studied catechol-O-methyltransferase (COMT) val158met variant (rs4680) codes for the COMT enzyme involved in dopamine degradation; the valine allele is associated with reduced prefrontal dopamine levels (Egan et al, 2001). With respect to schizophrenia treatment, the met allele is linked with improved working memory performance and reduced prefrontal cortical activity after 8 weeks of treatment with olanzapine (Bertolino et al, 2004); however, this study did not include a placebo condition for comparison. In the context of drugs of abuse that increase dopamine release, individuals with the val/val genotype show improved prefrontal efficiency (reduced activity at the same level of performance) during working memory performance following amphetamine administration (Mattay et al, 2003), whereas smokers with $\mathrm{val} / \mathrm{val}$ genotypes show improved performance and increased prefrontal activity following nicotine exposure $v s$ abstinence (Loughead et al, 2009). The $\mathrm{T}$ allele of the dopamine $\mathrm{D} 2$ receptor (DRD2) C957T variant, considered a reduced activity variant (Hirvonen et al, 2009), is also associated with reduced working memory and processing efficiency following nicotine administration (Jacobsen et al, 2006). Although it is difficult to draw conclusions from a single study of psychiatric treatment, emerging data on the effects of drugs of abuse suggest that individuals who carry putative reduced activity alleles for genes related to dopamine signaling may be more responsive to the cognitive enhancing effects of stimulating drugs. To expand the pool of pharmacogenomic markers to assess medication or drug effects on working memory or other domains of executive cognitive function, a focus on variants identified in genome-wide association studies (GWAS) for association with psychiatric conditions or neurocognitive phenotypes may be fruitful (Tost et al, 2012). However, despite the identification of novel molecular targets based on genomic analysis, the lack of consistency in phenotype assessment is a rate-limiting factor.

A potential area for improvement for these cognitive imaging phenotypes would be standardization of tasks across the field to facilitate comparisons between studies. Toward this end, the NIMH-funded Cognitive Neuroscience Treatment Research to Improve Cognition in Schizophrenia (CNTRICS) is establishing standardized batteries that measure cognitive functions most affected in schizophrenia (Carter et al, 2012). Proposed CNTRICS tasks probe domainspecific cognitive performance with discrete neural correlates, seeking to avoid ambiguous interpretations. For example, working memory tasks proposed by the CNTRICS initiative (Carter et al, 2012) are designed to probe different aspects of working memory (ie, goal maintenance, item maintenance, capacity, and interference control). Thus, the use of multiple cognitive tasks may permit investigators to distinguish genetic associations with medication effects on discrete cognitive domains $v s$ generalized cognitive deficits and neurobiological changes associated with psychiatric illness. Similarly, substance abuse results in long-term neuroadaptive changes, a process that may also be influenced by genetic factors. It is therefore difficult to disentangle preexisting risk factors from the effects of gene by drug exposure interactions in chronic drug users. Furthermore, fMRI studies of cognitive function in addiction have yet to incorporate both genotype and pharmacotherapy, and instead have focused only on effects of administration (or withdrawal) from drugs of abuse. Addiction research may benefit from adopting a similar approach to the CNTRICS initiative and establishing standardized neurocognitive batteries to evaluate genetic influences on treatment response.

\section{Emotional Face Processing Assessed with fMRI}

Through deconstructing cognition as a whole into discrete domains, one can also test seemingly non-cognitive facets of psychiatric disorders targeted by treatment, such as perception and social/emotional processing. CNTRICS suggests addressing aspects of positive and negative symptoms in schizophrenia by measuring perception and social/emotional processing (Carter et al, 2012), and these measures have shown some promise for predicting antidepressant treatment outcomes (Arnone et al, 2012; Rosenblau et al, 2012). Although little work has been done utilizing a pharmacogenetic approach to optimize treatment, initial studies in major depressive disorder provide one model for future research.

Although the endogenous cannabinoid system and neuropeptide Y (NPY) are not targeted directly by current anti-depressant treatments, recent work suggests that genetic variants in these systems that are associated with poor treatment outcomes contribute to impaired emotional processing. For example, the $\mathrm{G}$ allele of the CNR1 variant rs1049353 is associated with poorer antidepressant response and weaker striatal and thalamic response to happy faces (Domschke et al, 2008), whereas a genetic variant conferring reduced expression of NPY (the rs16147 C allele) is associated with greater amygdala reactivity to emotional faces in depressed patients, and with poorer treatment 
Table I Imaging Pharmacogenetic Studies in Psychiatric Disorders

\begin{tabular}{|c|c|c|}
\hline Imaging phenotype & Gene, SNP & Treatment \\
\hline $\begin{array}{l}\text { Working memory-related } \\
\text { activity measured by }\end{array}$ & $\begin{array}{l}\text { COMT val I 58met, } \\
\text { rs } 4680^{\mathrm{a}}\end{array}$ & Olanzapine \\
\hline
\end{tabular}

BOLD fMRI

DRD2 C957T $^{\mathrm{b}}$

Emotional face processing CNR/ rsI049353c during BOLD fMRI

Cue reactivity during
BOLD $\mathrm{AMRI}$ or perfusio MRI

CHRNA5

rs $16969968^{\circ}$

DRD4 VNTR

CYP2A6 ${ }^{\circ}$

Cue reactivity during

MRI

Various antidepressant treatments

NPY rs $16147^{\circ}$

DATI VNTR ${ }^{h}$

Nicotine
BOLD $\mathrm{fMRI}$ or perfusion

GABRA2 rs $27987 \mid$

Alcohol

DRD4 VNTR ${ }^{f}$

Cue reactivity during

BOLD fMRI or perfusion

MRI

SNCA rs2583985

Alcohol

OPRM I AII8G,

rsl79997/ ${ }^{k}$
Subjects and study design

$N=30$ schizophrenia patients, drug-free

at study start, completed 8 weeks of

olanzapine treatment. 20 completed PMRI

scans with $\mathrm{N}$-back task at 4 and 8 weeks of treatment.

$N=27$ healthy adults completed two fMRI sessions with $\mathrm{N}$-back task: after single $0.25 \mathrm{mg} / \mathrm{kg}$ dose of dextroamphetamine and after placebo (double-blind, order counterbalanced)

$N=33$ healthy smokers completed two fMRI sessions with n-back task: smoking satiety and after $\sim 12 \mathrm{~h}$ /overnight abstinence (order counterbalanced)

$N=36$ adult subjects (22 smokers and 14 nonsmokers) completed two fMRI sessions with n-back: nicotine patch and placebo patch (double-blind, order counterbalanced)

$N=256$ patients with major depression (MD) completed 6 weeks of treatment $n=33$ completed fMRI with emotional $n=33$ completed $\mathrm{fMRI}$
faces task at study start

$N=256$ patients with major depression completed 6 weeks of antidepressant treatment; a subset of $n=35$ patients completed $\mathrm{fMRI}$ scan with emotional faces task at study start (This sample overlaps with Domschke et al, 2008.)

$N=24$ female smokers completed $\mathrm{PMRI}$ scan with visual smoking cue reactivity task

$N=15$ smokers completed $\mathrm{fMRI}$ scan with visual smoking cue reactivity task after $2 \mathrm{~h}$ of smoking abstinence

$N=3 \mid$ smokers (fast vs slow nicotine metabolizers) completed $\mathrm{fMRI}$ scan with visual smoking cue reactivity task

$N=19$ smokers completed two perfusion $\mathrm{fMRI}$ scan sessions: smoking cue and neutral cue exposure, approximately I h apart

$N=35$ smokers completed an attentiona bias task before perfusion MRI scan with smoking cue paradigm

$N=26$ smokers completed perfusion MR with neutral and smoking cue video exposures

$N=40$ adults (social drinkers, nondependent heavy drinkers with and without family history of alcoholism) completed two separate fMRI scans with alcohol odor cue paradigm (alcohol cue vs appetitive control cue): one with IV alcohol infusion and one with IV saline infusion (order randomized)

$N=73$ heavy drinkers completed $\mathrm{AMRI}$ scan with alcohol taste cue paradigm

$N=326$ heavy drinkers completed $\mathrm{fMRI}$ with alcohol taste cue paradigm

$N=73$ heavy drinkers completed $\mathrm{fMRI}$ scan with alcohol taste cue paradigm

\section{Outcome}

Met/met (vs val/**) show improved performance and reduced prefrontal

activation after 8 weeks of treatment; no genotype differences at 4 weeks.

$\mathrm{Val} / \mathrm{val}$ show increased prefrontal efficiency (ie, reduced BOLD signal for same level of performance) after amphetamine vs placebo; met/met show decreased efficiency after amphetamine vs placebo, but only at the highest memory load

$\mathrm{Val} /$ val show reduced performance and reduced $B O L D$ signal in prefrontal cortex during nicotine abstinence vs smoking; no abstinence effect in met/*

$\mathrm{T} / *$ (vs C/C) show reduced performance and processing efficiency in left anterior insula, left cerebellum, bilateral mid occipital gyrus, and right fusiform gyrus following nicotine vs placebo

$\mathrm{G} /$ * vs (A/A) show poorer treatment response: $A$ ** (vs $G / G$ ) show stronger striatal and thalamic BOLD response to happy faces

C/* (vs T/T) associated with poorer treatment response in overall sample, and stronger BOLD response in the

amygdala to sad and angry faces in

imaging subsample.

G/G (vs A**) show increased cue reactivity in regions related to memory and habitual responding

7-Repeat allele (vs < 7-repeats) associated with increased cue reactivity to visual cues in reward regions; smoking cue by genotype interaction on craving

Fast (vs slow) nicotine metabolizers show increased smoking cue reactivity in reward regions

9-Repeat allele (vs 10-repeat homozygotes) associated with greater reactivity in the ventral striatal/pallidal/ orbitofrontal cortex regions to visual and tactile smoking cues.

9-Repeat carriers (vs 10-repeat homozygotes) showed positive correlation between attentional bias to smoking cues and increased cue reactivity in the amygdala

Presence of 9-repeat allele associated with greater reactivity in ventral striatum and medial orbitofrontal cortex

A/A (vs */G) show enhanced BOLD signal in response to cues in medial prefrontal cortex; reduced BOLD signal in ventral tegmental area; increased risk of dependence; and reduced 'high' during alcohol infusion

Presence of 7-repeat allele associated with increased reactivity to taste cues in reward regions before alcohol priming dose; no genotype difference after the priming dose

A/* (vs $G / G$ ) show increased reactivity to taste cues in caudate and paracingulate regions

G/* vs A/A show increased reactivity to taste cues in reward regions before and after alcohol priming
Reference

Bertolino et al (2004)

Mattay et al (2003)

Loughead et al

Jacobsen et al (2006)

Domschke et al (2008)

Domschke et al

Janes et al (20|2)

McClernon et al

(2007)

Tang et al (20|2)

Franklin et al (2009)

Wetherill et al (20|2)

Franklin et al (20। I)

Kareken et al (2010)

Filbey et al (2008)

Wilcox et al (2013)

Filbey et al (2008) 
Table I (Continued)

\begin{tabular}{|c|c|c|c|c|c|}
\hline Imaging phenotype & Gene, SNP & Treatment & Subjects and study design & Outcome & Reference \\
\hline & & Alcohol/naltrexone & $\begin{array}{l}N=74 \text { adult } A D \text { individuals completed } \\
\text { fMRI scan with alcohol cue paradigm on } \\
\text { day } 6 \text { of a } 7 \text {-day treatment with } \\
\text { naltrexone or placebo (randomized, } \\
\text { double-blind) }\end{array}$ & $\begin{array}{l}\mathrm{G} / * \text { vs } \mathrm{A} / \mathrm{A} \text { show increased cue } \\
\text { reactivity to alcohol taste and visual } \\
\text { cues in reward regions in placebo- } \\
\text { treated individuals, but nominally lower } \\
\text { cue reactivity in individuals treated with } \\
\text { naltrexone }\end{array}$ & Schacht et al (20|3) \\
\hline & CNRI rs2023239' & Cannabis & $\begin{array}{l}N=43 \text { marijuana users completed } \mathrm{fMRI} \\
\text { scan with cue reactivity paradigm } \\
\text { following } 72 \mathrm{~h} \text { abstinence }\end{array}$ & $\begin{array}{l}\text { G/A vs A/A show enhanced cue } \\
\text { reactivity to tactile cues in reward } \\
\text { regions, increased cannabis withdrawal, } \\
\text { and increased craving }\end{array}$ & Filbey et al (2010) \\
\hline & $\begin{array}{l}\text { FAAH C } 385 A \\
\text { rs } 324420^{\mathrm{m}}\end{array}$ & & $\begin{array}{l}N=43 \text { marijuana users completed } \mathrm{PMRI} \\
\text { scan with cue reactivity paradigm } \\
\text { following } 72 \mathrm{~h} \text { abstinence }\end{array}$ & $\begin{array}{l}\mathrm{C} / \mathrm{C} \text { (vs } \mathrm{A} / * \text { *) show increased response } \\
\text { to marijuana cues in reward regions. } \\
\text { Combined number of risk alleles for } \\
\text { FAAH rs } 324420 \text { plus CNR/ rs } 2023239 \\
\text { was positively correlated with cue } \\
\text { reactivity }\end{array}$ & Filbey et al (2010) \\
\hline CBF & DATI VNTR ${ }^{h}$ & Methylphenidate & $\begin{array}{l}N=8 \text { male treatment-naïve children with } \\
\text { ADHD received methylphenidate for } 4 \\
\text { days before SPECT imaging session }\end{array}$ & $\begin{array}{l}\text { Presence of I0-repeat allele associated } \\
\text { with higher regional CBF in medial } \\
\text { frontal and left basal ganglia regions, } \\
\text { and with poorer treatment response. }\end{array}$ & Rohde et al (2003) \\
\hline \multirow[t]{3}{*}{ CBF } & $\begin{array}{l}\text { OPRMI A|l|8G, } \\
\text { rs }\left.179997\right|^{k}\end{array}$ & Nicotine & $\begin{array}{l}N=15 \text { healthy smokers completed two } \\
\text { arterial spin labeled (ASL) perfusion MRI } \\
\text { scans: smoking as usual and overnight } \\
\text { abstinence (order counterbalanced) }\end{array}$ & $\begin{array}{l}\mathrm{A} / \mathrm{A} \text { (vs G/*) show greater increases in } \\
\mathrm{CBF} \text { in regions associated with cravings } \\
\text { during nicotine abstinence vs satiety }\end{array}$ & Wang et al (2008) \\
\hline & $D R D 2-|4| C^{n}$ & & & $\begin{array}{l}\text { DelC/InsC (vs InsC/InsC) show greater } \\
\text { increases in CBF in regions associated } \\
\text { with cravings during nicotine abstinence } \\
\text { vs satiety }\end{array}$ & \\
\hline & $\begin{array}{l}\text { COMT val I 58met, } \\
\text { rs } 4680^{\mathrm{a}}\end{array}$ & & & $\begin{array}{l}\text { val/val (vs met/*) show greater } \\
\text { increases in CBF in regions associated } \\
\text { with cravings during nicotine abstinence } \\
\text { vs satiety }\end{array}$ & \\
\hline \multirow[t]{3}{*}{$\begin{array}{l}\text { Structural abnormalities } \\
\text { based on MRI }\end{array}$} & AKTI rs I $30233^{\circ}$ & $\begin{array}{l}\text { Lithium and sodium } \\
\text { valproate }\end{array}$ & $\begin{array}{l}N=138 \text { schizophrenic patients with } \\
\text { complete pharmacological, cognitive, and } \\
\text { structural MRI data from the Clinical Brain } \\
\text { Disorders Branch Sibling Study }\end{array}$ & $\begin{array}{l}\mathrm{A} / * \text { genotype (vs } \mathrm{G} / \mathrm{G} \text { ) associated with } \\
\text { increased gray matter volume in the } \\
\text { medial temporal lobe and prefrontal } \\
\text { cortex, and reduced cognitive } \\
\text { deterioration following treatment with } \\
\text { mood stabilizers. }\end{array}$ & Tan et al (2012) \\
\hline & $\begin{array}{l}\text { BDNF val66met, } \\
\text { rs } 6265^{\circ}\end{array}$ & $\begin{array}{l}\text { Various } \\
\text { antidepressant } \\
\text { treatments }\end{array}$ & $\begin{array}{l}N=37 \text { adults completed structural MRI } \\
\text { scan within } 2 \text { weeks of hospital admission } \\
\text { for treatment of current major depressive } \\
\text { episode }\end{array}$ & $\begin{array}{l}\text { Inverse correlation between gray } \\
\text { matter volume in right orbitofrontal } \\
\text { cortex and time to symptom remission } \\
\text { in met carriers, but not val/val } \\
\text { individuals }\end{array}$ & Cardoner et al (20।3) \\
\hline & & Escitalopram & $\begin{array}{l}N=32 \text { elderly patients with unipolar } \\
\text { depression;2-week single-blind placebo } \\
\text { drug-washout before MRI scan; followed } \\
\text { by } 12 \text { weeks of treatment with } \\
\text { escitalopram }\end{array}$ & $\begin{array}{l}\text { */met ( } \mathrm{vs} \mathrm{val} / \mathrm{val}) \text { and white matter } \\
\text { abnormalities independently predict } \\
\text { remission }\end{array}$ & $\begin{array}{l}\text { Alexopoulos et al } \\
(20 \mid 0)\end{array}$ \\
\hline \multirow[t]{2}{*}{$\begin{array}{l}\text { MOR availability based on } \\
\text { PET }\end{array}$} & $\begin{array}{l}\text { OPRM I A I I8G, } \\
\text { rs }\left.179997\right|^{k}\end{array}$ & Nicotine & $\begin{array}{l}N=22 \text { smokers completed two PET } \\
\text { sessions after overnight abstinence: after } \\
\text { smoking a nicotine-containing cigarette } \\
\text { and after a placebo cigarette }\end{array}$ & $\begin{array}{l}\text { A/A vs G/* show greater MOR } \\
\text { availability during both sessions; no } \\
\text { genotype } \times \text { session interaction }\end{array}$ & Ray et al (20। I) \\
\hline & & Alcohol, Naltrexone & $\begin{array}{l}N=25 \text { AD adults and } 28 \text { healthy controls. } \\
\text { AD subjects completed PET scan on day } \\
5 \text {, naltrexone on days } 15-18 \text {, and post- } \\
\text { treatment PET scan on day } 18\end{array}$ & $\begin{array}{l}\text { A/A vs */G show increased MOR } \\
\text { availability at baseline. Nonsignificant } \\
\text { trend toward reduced availability after } \\
\text { naltrexone in G/* vs A/A }\end{array}$ & Weerts et al (20|2) \\
\hline $\begin{array}{l}\text { SERT occupancy based on } \\
\text { SPECT }\end{array}$ & 5-HTTLPR & Paroxetine & $\begin{array}{l}N=42 \text { drug-naïve or currently drug-free } \\
\text { depressed adults completed SPECT scan } \\
\text { at baseline and after } 6 \text { weeks of open- } \\
\text { label paroxetine }\end{array}$ & $\begin{array}{l}\text { Higher SERT occupancy in the } \\
\text { diencephalon associated with greater } \\
\text { symptom improvement in } L_{A} / *{ }^{*} S^{0} / S^{0} \\
\text { similar effect in midbrain for } L_{A} / L_{A} v S \\
S^{0} / *\end{array}$ & Ruhe et al (2009) \\
\hline \multirow[t]{2}{*}{$\begin{array}{l}\text { Dopamine transporter } \\
\text { availability or occupancy } \\
\text { based on PET or SPECT }\end{array}$} & DATI VNTR ${ }^{h}$ & Methylphenidate & $\begin{array}{l}N=\text { II drug naïve children with } \mathrm{ADHD} \\
\text { completed } 8 \text { weeks of } \mathrm{MPH} \text { treatment }\end{array}$ & $\begin{array}{l}\text { Homozygosity for 10-repeat allele } \\
\text { associated with greater DAT availability } \\
\text { in basal ganglia following treatment and } \\
\text { poorer treatment response compared } \\
\text { with } 9 \text { R carriers }\end{array}$ & Cheon et al (2005) \\
\hline & $\begin{array}{l}\text { DATI VNTR } \\
\text { X } \\
\text { DRD4 VNTR }\end{array}$ & & $\begin{array}{l}N=17 \text { male adolescents with comorbid } \\
\text { ADHD and substance abuse completed } \\
\text { SPECT scans before and after } 3 \text { weeks of } \\
\text { methylphenidate treatment }\end{array}$ & $\begin{array}{l}\text { Individuals with both DATI I0-repeat } \\
\text { and DRD4 7-repeat genotypes show } \\
\text { reduced blockade of DAT (less change } \\
\text { in availability pre- to post-treatment) in } \\
\text { the caudate and putamen }\end{array}$ & Szobot et al (201 I) \\
\hline \multirow[t]{2}{*}{$\begin{array}{l}\text { Dopamine receptor } \\
\text { availability based on PET }\end{array}$} & $\begin{array}{l}\text { OPRMI A|I8G, } \\
\text { rs }\left.179997\right|^{k}\end{array}$ & Alcohol & $\begin{array}{l}N=28 \text { male social drinkers completed } \\
\text { two [ ' } C \text { raclopride PET scans sessions: IV } \\
\text { alcohol infusion vs placebo infusion }\end{array}$ & $\begin{array}{l}\text { G/* vs A/A show increased DA release } \\
\text { following alcohol challenge }\end{array}$ & $\begin{array}{l}\text { Ramchandani et al } \\
(20 \mid \mathrm{I})\end{array}$ \\
\hline & DATI VNTR ${ }^{h}$ & Nicotine & $\begin{array}{l}N=45 \text { healthy smokers completed one } \\
{ }^{11} \text { C] } \text { raclopride PET scans sessions during } \\
\text { which they either smoked }(n=35) \text { or did } \\
\text { not smoke }(n=10) \text { during a break in } \\
\text { scanning }\end{array}$ & $\begin{array}{l}\text { 9-Repeat carriers (vs I0-repeat } \\
\text { homozygotes) showed greater } \\
\text { decreases in binding potential (ie, } \\
\text { greater dopamine release) in the } \\
\text { ventral caudate/nucleus accumbens } \\
\text { after smoking a cigarette }\end{array}$ & (Brody et al, 2006) \\
\hline
\end{tabular}


Table I (Continued)

\begin{tabular}{|c|c|c|c|c|c|}
\hline Imaging phenotype & Gene, SNP & Treatment & Subjects and study design & Outcome & Reference \\
\hline & DRD4 VNTR ${ }^{f}$ & & $\begin{array}{l}N=45 \text { healthy smokers completed one } \\
\text { [ ' } C \text { C]raclopride PET scans sessions during } \\
\text { which they either smoked }(n=35) \text { or did } \\
\text { not smoke }(n=10) \text { during a break in } \\
\text { scanning }\end{array}$ & $\begin{array}{l}<7 \text {-Repeat carriers (vs 7-repeat } \\
\text { homozygotes) showed greater } \\
\text { decreases in binding potential (ie, } \\
\text { greater dopamine release) in the } \\
\text { ventral caudate/nucleus accumbens } \\
\text { after smoking a cigarette }\end{array}$ & \\
\hline & $\begin{array}{l}\text { COMT vall } 58 \text { met, } \\
\text { rs } 4680^{a}\end{array}$ & & & $\begin{array}{l}\text { Val/val (vs */met) associated with } \\
\text { greater decreases in binding potential } \\
\text { (ie, greater dopamine release) in the } \\
\text { ventral caudate/nucleus accumbens } \\
\text { after smoking a cigarette }\end{array}$ & \\
\hline $\begin{array}{l}\text { Axial diffusivity based on } \\
\text { diffusion tensor imaging }\end{array}$ & GSK3- $\beta$ rs334558 & Lithium & $\begin{array}{l}N=70 \text { bipolar patients ( } 50 \text { untreated, } 20 \\
\text { treated chronically with lithium at study } \\
\text { start) completed a single DTI scan session }\end{array}$ & $\begin{array}{l}\text { */C (vs T/T) genotype and long-term } \\
\text { lithium treatment were independently } \\
\text { associated with increased axial } \\
\text { diffusivity in white matter tracts }\end{array}$ & Benedetti et al (20|3) \\
\hline
\end{tabular}

Abbreviations: AD, alcohol dependent; CBF, cerebral blood flow; MOR, Mu-opioid receptor; SERT, serotonin transporter.

aMet allele codes for lower activity protein because of thermal instability; associated with higher intracellular DA levels due to decreased degradation, and typically associated with better performance on executive function tasks (Egan et al, 200 I).

${ }^{\mathrm{b}} \mathrm{T}$ allele associated with reduced mRNA stability, lower expression of DRD2 receptors, and reduced receptor affinity (Hirvonen et al, 2009).

'Synonymous SNP; functional consequences uncertain (Domschke et al, 2008).

${ }^{\mathrm{d}} \mathrm{C}$ allele associated with reduced gene expression, reduced affinity for an as-yet-unknown factor. NPY is anxiolytic; $\mathrm{C}$ allele associated with anxiety and depressive symptoms (Sommer et al, 20I0).

${ }^{\mathrm{e}} \mathrm{A}$ allele associated with reduced receptor sensitivity, increased risk of nicotine dependence, increased smoking quantity (Bierut et al, 2008).

${ }^{{ }_{7}}$-Repeat allele associated with reduced receptor sensitivity (Asghari et al, 1995).

gFaster nicotine metabolizers smoke more and have greater difficulty quitting (Schnoll et al, 2009).

hHomozygosity for the 10-repeat allele associated with increased DAT expression compared with 9-repeat carriers (Fuke et al, 200 I).

iFunctional consequences uncertain, but suspected to alter gene expression (Kareken et al, 2010).

${ }^{\mathrm{j}}$ Functional consequences uncertain, but suspected to alter gene expression (Wilcox et al, 20।3).

${ }^{k} \mathrm{G}$ allele associated with reduced mRNA and protein levels and reduced binding affinity (Mague et al, 2009).

'Functional consequences uncertain, but may code a splice variant (Zhang et al, 2004).

${ }^{m} \mathrm{~A}$ allele associated with reduced expression and lower stability of FAAH (Chiang et al, 2004).

${ }^{\mathrm{n}}$ DelC variant associated with increased receptor density (Jonsson et al, 1999).

'Synonymous variant; A allele associated with reduced protein expression, reduced cognitive performance vs */G (Blasi et al, 20l I).

PMet allele inhibits activity-dependent secretion of BDNF; no effect on mature protein function. Met allele associated with worse memory performance, lower hippocampal volume/activation, impaired synaptic transmission, etc. (Egan et al, 2003).

${ }^{\mathrm{q}} \mathrm{L}$ allele associated with higher concentrations of SERT mRNA (increased transcription) and with twofold higher serotonin uptake (L homozygotes); S allele associated with increased anxiety-related traits and increased risk of depression following stress (Lesch and Gutknecht, 2005).

rPromoter region SNP; T allele associated with greater activity (Kwok et al, 2005).

*, Any allele.

response among a subgroup of patients with anxious depression (Domschke et al, 2010).

Although limbic reactivity to emotional faces may provide a useful measure to identify likely treatment responders or for early medication screening, important limitations of these studies include the combined analysis of patients taking a range of medications (eg, tricyclics, SSRIs, neuroleptics) and the lack of randomization to medication $v s$ placebo. Thus, the treatment component of these studies was incidental, rather than an imaging pharmacogenetic approach. Future studies selecting genetic variants based on drug targets and metabolizing enzymes, and testing gene $\times$ treatment interactions would be a promising extension of this work.

\section{Cue Reactivity Assessed with fMRI or Perfusion MRI}

Cue-induced cravings (ie, intense, acute cravings triggered by drug-associated stimuli) contribute to addiction and relapse, and the pattern of cue-evoked neural responses (cue reactivity) in reward regions may provide a biomarker of relapse risk for addiction treatment (Sinha and Li, 2007).
Cue reactivity may therefore provide an imaging phenotype for assessing individual factors, which influence treatment response. A majority of studies have focused on genetic variation in the dopamine system. For example, the 7-repeat allele of a common variable number tandem repeat (VNTR) in the dopamine $\mathrm{D} 4$ receptor (DRD4) gene, associated with decreased dopaminergic tone and increased craving (Hutchison et al, 2002), is associated with enhanced cue reactivity in drug reward-related regions among alcohol drinkers and regular smokers (McClernon et al, 2007; Filbey et al, 2008). The SNCA rs2583985 A allele, which may alter alpha synuclein expression in dopaminergic neurons, was also associated with increased cue reactivity in heavy drinkers (Wilcox et al, 2013). The 9-repeat allele of the dopamine transporter gene (DAT1, also called SLC6A3) VNTR is associated with increased reactivity in the ventral striatum and medial orbitofrontal cortex to smoking cues $v s$ neutral cues in two independent studies (Franklin et al, 2009; Franklin et al, 2011); a positive correlation between increased activation in the amygdala and attentional bias for smoking cues was also noted in carriers of the 9-repeat allele (Wetherill et al, 2012). 
Additional peptide and neurotransmitter systems may also have a role in cue reactivity. Alcohol increases release of endogenous opioid peptides that bind to mu-opioid receptors. The $\mathrm{G}$ allele of the mu-opioid receptor (OPRM1) A118G variant has been associated with increased alcohol cue reactivity in regular and heavy drinkers (Filbey et al, 2008), an effect that may be reversed following treatment with the mu-opioid receptor antagonist naltrexone (Schacht et al, 2013). Cannabinoid receptor signaling may mediate the effects of alcohol on dopamine release on the ventral tegmental area (VTA; Pava and Woodward, 2012), and the CNR1 rs2023239 G allele, conferring increased cannabinoid receptor binding ( $v s$ A allele), is associated with enhanced drug cue reactivity in regular alcohol drinkers (Hutchison et al, 2008) as well as cue reactivity in regular marijuana users (Filbey et al, 2010). Variation in CNR1 may also impact nicotine dependence (Chen et al, 2008b), although to our knowledge this has not been examined in neuroimaging cue reactivity studies in smokers.

Some genetic influences on neural cue reactivity may be specific to different drugs of abuse. Homozygosity for the gamma-aminobutyric acid receptor subunit alpha-2 gene (GABRA2) rs279871 A allele increases risk for developing alcohol dependence (Edenberg et al, 2004). Drinkers homozygous for this allele show increased reactivity to alcohol taste cues in the medial prefrontal cortex but decreased reactivity in the VTA; the apparently discordant findings across brain regions may reflect cue-evoked inhibitory responses in the VTA (Kareken et al, 2010). Of relevance to marijuana use, fatty acid amide hydrolase (FAAH) metabolically inactivates the endogenous cannabinoid anandamide; the A allele of the FAAH variant rs 324420 is associated with lower risk of cannabis dependence (Tyndale et al, 2007) and reduced responses to marijuana tactile cues in regular cannabis users (Filbey et al, 2010). In the context of nicotine dependence, homozygosity for the G allele of the alpha- 5 subunit of the nicotinic acetylcholine receptor gene (CHRNA5) rs16969968, which may increase nicotinic acetylcholine receptor activation (Bierut et al, 2008), is associated with enhanced cue reactivity in several cortical and subcortical brain regions in nicotine-dependent women (Janes et al, 2012). Enhanced cue reactivity has also been documented in faster metabolizers of nicotine (Tang et al, 2012), who relapse at higher rates than slower metabolizers (Lerman et al, 2006; Schnoll et al, 2009). With one notable exception (Schacht et al, 2013), none of these studies incorporated genetic and neuroimaging analysis of cue reactivity into clinical trials testing different therapies for addiction. However, these initial studies suggest that cue reactivity may be a promising intermediate phenotype for examining mechanisms of individual differences in substance abuse treatment response.

\section{Regional Cerebral Blood Flow (CBF) Assessed with Perfusion MRI}

Regional CBF is thought to reflect localized metabolic activity, providing an alternate neuroimaging measure for pharmacogenetic research. Although abnormalities in CBF have long been associated with psychiatric disorders (Theberge, 2008), the application of arterial spin-labeled perfusion MRI to pharmacogenetic studies is still in an early stage. Methylphenidate (MPH), the most commonly prescribed medication for the treatment of attention-deficit hyperactivity disorder (ADHD), blocks the dopamine transporter and increases dopamine release. A VNTR in DAT1 increases DAT expression and has been linked to poorer response to MPH treatment for ADHD (Durston, 2010). In one study, the DAT1 10-repeat allele (10R) was associated with higher CBF in medial frontal and left basal ganglia areas among children following MPH treatment (Rohde et al, 2003), which may suggest greater dopamineinduced activation following treatment in children genetically predisposed to have more active dopamine reuptake. In a small preliminary study, genetic variants associated with greater risk of nicotine addiction were associated with increased $\mathrm{CBF}$ during nicotine withdrawal in regions associated with cravings, suggesting a possible mechanism for genetic vulnerability to addiction (Wang et al, 2008). However, the very small sample sizes in these studies limit interpretation of these findings.

\section{Structural Abnormalities Assessed with MRI}

Functional alterations commonly observed in psychiatric disorders may reflect underlying changes in brain structure (Michael et al, 2011; Kwaasteniet et al, 2013), suggesting an additional neuroimaging phenotype for pharmacogenetic studies. In MDD and $\mathrm{BD}$, for example, volumetric differences in the amygdala and basal ganglia have been noted for patients compared with healthy controls, although the direction of alterations differs: studies of MDD typically report smaller (but hyperactive) regions, whereas BD patients exhibit enlargements (Konarski et al, 2008). Volumetric reductions of the prefrontal cortex are common to both disorders (Konarski et al, 2008), and effective treatments for these disorders appear to normalize these structural and functional abnormalities (Drevets et al, 2002; Chen et al, 2008a; Savitz et al, 2010; Hafeman et al, 2012).

Although only a few studies have investigated genetic influences on antidepressant and anti-psychotic treatment response using structural MRI, preliminary efforts support this approach and highlight the role of neuronal growth factors in antidepressant response. An investigation into the effects of a variant the gene encoding the brain-derived neurotrophic factor (BDNF val66met) demonstrated an inverse correlation between gray matter volume in the right orbitofrontal cortex and time to symptom remission after antidepressant treatment was observed in carriers of the $B D N F$ met allele, but not in BDNF val homozygotes (Cardoner et al, 2013). In addition, the BDNF met allele and white matter abnormalities independently predict remission of depressive symptoms in patients with lateonset depression after treatment with escitalopram (Alexopoulos et al, 2010). We found only one study investigating pharmacogenetic imaging of $\mathrm{BD}$. Benedetti et al (2013) reported overlapping effects of lithium treatment and the reduced activity $\mathrm{C}$ allele of the GSK3- $\beta$ rs334558 promoter variant on measures of axial diffusivity in white matter fiber tracts in BD patients. However, the sample size for this study was too small to investigate gene by treatment interactions. In schizophrenic patients, a variant associated with reduced expression of a proteinregulating GSK3- $\beta$ activity (the AKT1 rs1130233 A allele) 
was associated with increased gray matter volume in the medial temporal lobe and prefrontal cortex, and with reduced cognitive deterioration following treatment with lithium or sodium valproate (Tan et al, 2012). BDNF and GSK3- $\beta$ both regulate neuronal growth and survival; relationships between these genetic variants and structural measures of treatment response support the hypothesis that antidepressant and lithium treatments may act through neurogenerative pathways, possibly simulating normal function in patients with genetic deficits in neurotrophic signaling.

\section{Receptor Availability or Transporter Occupancy Assessed with PET/Single-Photon Emission Computed Tomography (SPECT)}

Although molecular imaging techniques such as PET and SPECT may lack the temporal resolution of MRI, they offer unique advantages in elucidating pharmacological response at the receptor level. For example, VNTRs in DAT1 and DRD4 have been associated with increased risk of ADHD (Durston, 2010), because MPH, the most commonly prescribed medication for the treatment of ADHD, blocks the dopamine transporter and increases dopamine release, these variants are promising candidates for influencing treatment response. One SPECT study demonstrated that children homozygous for the DAT1 10R allele (thought to increase DAT expression and typically associated with increased risk of ADHD) had a greater increase in DAT density in the basal ganglia after MPH treatment and were less likely to experience a beneficial clinical response (Cheon et al, 2005). A more recent study demonstrated that a combination of the DAT1 10R/10R genotype with the DRD4 VNTR 7-repeat risk allele was associated with reduced blockade of DAT by MPH in adolescents comorbid for substance abuse (Szobot et al, 2011). The DRD4 7-repeat variant results in a less sensitive receptor (Asghari et al, 1995). Together, these results suggest that genetic traits that result in reduced dopamine signaling may diminish the effectiveness of MPH for treating ADHD. In contrast, genes associated with lower synaptic dopamine concentrations and normal dopamine receptor and transporter function are associated with greater smoking-induced dopamine release; subjects carrying at least one DAT1 9R allele, $<7$-repeats of the DRD4 VNTR, or who were homozygous for the COMT val allele showed a greater change in $\left[{ }^{11} \mathrm{C}\right]$ raclopridebinding potential in the ventral caudate and nucleus accumbens after smoking a cigarette (Brody et al, 2006). Genetic variation in the mu-opioid receptor, which has downstream effects on dopamine release, is also related to dopamine release following an alcohol challenge (Ramchandani et al, 2011).

SPECT imaging has been used to demonstrate a modifying effect of a serotonin transporter (SERT) gene promoter variant (5HTTLPR) on the relationship between SERT occupancy after treatment with paroxetine (a selective serotonin reuptake inhibitor, or SSRI) and 6-week symptom relief in MDD (Ruhe et al, 2009). Carriers of the 5HTTLPR $\mathrm{L}_{\mathrm{A}}$ genotype showed positive associations between SERT occupancy in the diencephalon and improvements in scores on the Hamilton Depression Rating Scale; in the midbrain, this effect was significant only for $\mathrm{L}_{\mathrm{A}}$ homozygotes. The $\mathrm{L}_{\mathrm{A}}$ variant is associated with increased SERT transcription and up to twofold higher serotonin uptake (Lesch and Gutknecht, 2005); this suggests that SSRI activity may be more relevant to treatment outcome in individuals predisposed to greater SERT availability, although this finding requires replication. Unfortunately, none of these studies included a placebo condition, precluding analysis of a gene $\times$ treatment interaction.

Finally, studies of the mu-opioid receptor variant OPRM1 A118G, which modulates receptor expression and binding affinity (Mague and Blendy, 2010), offer promising support for use of $\left[{ }^{11} \mathrm{C}\right]$ carfentanil PET imaging in this context. Homozygosity for the common A allele is associated with greater receptor availability in smokers, alcohol-dependent patients and healthy controls (Ray et al, 2011; Weerts et al, 2012). However, although the A allele is associated with increased risk of nicotine addiction, the $\mathrm{G}$ allele is more frequently a risk factor for alcohol dependence (Ray et al, 2012). Thus, associations between OPRM1 variation and molecular phenotype may depend on the specific drug of abuse (Mague and Blendy, 2010).

\section{SOME PITFALLS}

Although the findings presented above represent a major step forward in our understanding of the genetic underpinnings of aberrant neurocircuitry associated with neuropsychiatric disorders and their treatment, several issues should be considered. Although neuroimaging offers the advantage of detecting more subtle objectively measured phenotypes, the sample sizes tend to be small, due in part to the intensity and cost of these assessments. Consequently, these studies may be prone to detect spurious genetic associations; this is a particular problem with post-hoc genotyping of multiple candidate genes. Studies that incorporate prospective genotyping of functional variants with an a priori hypothesis can attenuate this problem to some extent, but replication is necessary. A focus on variants identified in GWAS of psychiatric illness is proving to be a useful approach in imaging genetic research (Tost et al, 2012). Moreover, integrating GWAS approaches with neuroimaging directly may lead to the identification of novel variants underlying treatment effects on brain structure and function. Although the volume of the data generated poses some challenges, appropriate correction procedures may address this (Meyer-Lindenberg et al, 2008). Furthermore, understanding the molecular basis of these novel variants is required to build polygenic models that accurately represent biological function.

Well-validated neuroimaging paradigms and use of standardized neurobehavioral task probes are critical to advance the field. Within fMRI, for example, there is tremendous variability in experimental paradigms and analytic approaches that contributes to false positive results (Carpentier et al, 2012). The issue of test-retest reliability is another consideration; some cognitive fMRI measures (such as the n-back working memory task) provide very good within-subject reproducibility, whereas others (such as the facial matching tasks) are more variable (Bennett and Miller, 2010; Plichta et al, 2012). Further, comorbidities in psychiatric populations can pose a significant challenge, and variability in screening criteria across studies may 
limit the reproducibility of findings. For example, nicotine dependence occurs at a substantial rate in persons with mood disorders, psychosis and other forms of addiction. However, despite well-documented effects of both smoking and nicotine withdrawal on neural activation and neurotransmitter regulation, few psychiatric imaging studies control for smoking status, smoking rate, or time since last use in any rigorous way.

An added consideration for the eventual use of neuroimaging phenotypes is the increased cost compared with standard behavioral and clinical measures, which may be prohibitive for some patients and therefore requires clear demonstration of added value. However, imaging measures do provide an objective assessment that does not rely on patient self-report or clinician judgment. Imaging may also provide a more sensitive measure, enabling more rapid feedback for treatment decisions and facilitating rapid screening of new medications. Imaging measures for medication screening may reduce the necessary sample size to demonstrate an effect (or lack thereof) in early clinical development. However, to achieve the promise of these approaches, study designs that randomize patients to treatment are necessary to test a pharmacogenetic hypothesis.

\section{CONCLUSION AND FUTURE DIRECTIONS}

The emerging integration of neuroimaging into psychiatric pharmacogenetics research has the potential to accelerate psychiatric treatment development and delivery. For example, neuroimaging studies are contributing to a more refined understanding of treatment targets by elucidating the neural circuits and neurochemical processes underlying a broader range of neurobehavioral phenotypes. These include: alterations in reward learning and response to reward, executive cognitive function, decision-making and behavioral control, emotional reactivity, and social processing. Resting state functional connectivity ( $\mathrm{rsFC}$ ) studies are providing additional insight into the role of large-scale network coupling in psychiatric disorders (Menon, 2011). These studies have demonstrated genetic influences on rsFC in schizophrenia, $\mathrm{MDD}$, and addiction, and suggest that rsFC may have the potential to predict treatment response (Hong et al, 2010; Liu et al, 2011; Chen et al, 2012; Jamadar et al, 2013). However, to our knowledge no studies have yet combined genetic analysis of $\mathrm{rsFC}$ with treatment in a psychiatric population, highlighting this as an area for further exploration. Further, neuroimaging of treatment effects on these targets can generate profiles of the effects of efficacious treatments on aberrant neural circuitry or neurochemistry, providing a biomarker of treatment response against which novel compounds can be compared and selected for future development. For example, a demonstration that tolcapone, a COMT inhibitor approved for treatment of Parkinson's disease, significantly improved cortical efficiency during tasks assessing executive function in healthy individual homozygous for the val allele of the COMT val158met variant (Apud et al, 2007) has inspired research into genotype-based tolcapone treatment of cognitive impairments in schizophrenia (Apud et al, 2007; Roussos et al, 2009). Incorporating genetics into these studies can provide an assay of individual differences in treatment response, enabling the development of medications that are targeted to particular genotypic groups. The identification of treatment responders and non-responders using a combination of genetic and neuroimaging approach may thus provide a more powerful strategy for targeted therapy than either tool alone (Ray et al, 2008).

\section{FUNDING AND DISCLOSURE}

Dr Lerman has served as a consultant for and/or has received research funding from GlaxoSmithKline, AstraZeneca, and Pfizer. In the past three years she has also received honoraria or compensation from the NIH, University of California Los Angeles, Washington University, Ohio State University, Yale University, University of North Carolina, University of Chicago, Indiana University, Memorial Sloan Kettering, University of New Mexico, and Moffitt Cancer Center. Dr Tyndale has participated in one day advisory meetings for Novartis (2008) and McNeil (2011). Ms Chenoweth has received support within the past 3 years from a Canadian Institutes of Health Research (CIHR) Frederick Banting 16 and Charles Best Canada Graduate Scholarship Doctoral Award. The other authors declare no conflict of interest. This work was supported by NIH Grants R01 DA026849; Pharmacogenetics Research Network Grants DA U0102830, U01 GM092655, and U01 MH092758-03; P50 CA143187; T32 GM008076; and Grants from the Center for Addiction and Mental Health and the Canada Foundation for Innovation (\#20289, \#16014), the CAMH Foundation and the Ontario Ministry of Research and Innovation, and the Endowed Chair in Addictions for the Department of Psychiatry.

\section{REFERENCES}

Alexopoulos GS, Glatt CE, Hoptman MJ, Kanellopoulos D, Murphy CF, Kelly RE Jr et al (2010). BDNF val66met polymorphism, white matter abnormalities and remission of geriatric depression. J Affect Disord 125: 262-268.

Apud JA, Mattay V, Chen J, Kolachana BS, Callicott JH, Rasetti R et al (2007). Tolcapone improves cognition and cortical information processing in normal human subjects. Neuropsychopharmacol 32: 1011-1020.

Arnone D, McKie S, Elliott R, Thomas EJ, Downey D, Juhasz G et al (2012). Increased amygdala responses to sad but not fearful faces in major depression: relation to mood state and pharmacological treatment. Am J Psychiatr 169: 841-850.

Asghari V, Sanyal S, Buchwaldt S, Paterson A, Jovanovic V, Van Tol HH (1995). Modulation of intracellular cyclic AMP levels by different human dopamine D4 receptor variants. J Neurochem 65: 1157-1165.

Ashare RL, Falcone M, Lerman C (2013). Cognitive function during nicotine withdrawal: implications for nicotine dependence. Neuropharmacology; epub ahead of print 29 April 2013. doi:10.1016/j.neuropharm.2013.04.034.

Benedetti F, Bollettini I, Barberi I, Radaelli D, Poletti S, Locatelli C et al (2013). Lithium and GSK3-beta promoter gene variants influence white matter microstructure in bipolar disorder. Neuropsychopharmacol 38: 313-327.

Bennett CM, Miller MB (2010). How reliable are the results from functional magnetic resonance imaging? Ann NY Acad Sci 1191: 133-155.

Bertolino A, Caforio G, Blasi G, De Candia M, Latorre V, Petruzzella V et al (2004). Interaction of COMT (Val(108/ 158)Met) genotype and olanzapine treatment on prefrontal 
cortical function in patients with schizophrenia. Am J Psychiatr 161: 1798-1805.

Bierut LJ, Stitzel JA, Wang JC, Hinrichs AL, Grucza RA, Xuei X et al (2008). Variants in nicotinic receptors and risk for nicotine dependence. Am J Psychiatr 165: 1163-1171.

Blasi G, Napolitano F, Ursini G, Taurisano P, Romano R, Caforio G et al (2011). DRD2/AKT1 interaction on D2 c-AMP independent signaling, attentional processing, and response to olanzapine treatment in schizophrenia. Proc Natl Acad Sci USA 108: $1158-1163$.

Brody AL, Mandelkern MA, Olmstead RE, Scheibal D, Hahn E, Shiraga S et al (2006). Gene variants of brain dopamine pathways and smoking-induced dopamine release in the ventral caudate/nucleus accumbens. Arch Gen Psychiatr 63: 808-816.

Cardoner N, Soria V, Gratacos M, Hernandez-Ribas R, Pujol J, Lopez-Sola M et al (2013). Val66met Bdnf genotypes in melancholic depression: effects on brain structure and treatment outcome. Depress Anxiety 30: 225-233.

Carpentier PJ, Arias Vasquez A, Hoogman M, Onnink M, Kan CC, Kooij JJ et al (2012). Shared and unique genetic contributions to attention deficit/hyperactivity disorder and substance use disorders: A pilot study of six candidate genes. Eu Neuropsychopharmacol 23: 448-457.

Carter CS, Barch DM, Committee CE (2012). Imaging biomarkers for treatment development for impaired cognition: report of the sixth CNTRICS meeting: biomarkers recommended for further development. Schizophr Bull 38: 26-33.

Chen $\mathrm{CH}$, Suckling J, Ooi C, Fu CH, Williams SC, Walsh ND et al (2008a). Functional coupling of the amygdala in depressed patients treated with antidepressant medication. Neuropsychopharmacol 33: 1909-1918.

Chen X, Williamson VS, An SS, Hettema JM, Aggen SH, Neale MC et al (2008b). Cannabinoid receptor 1 gene association with nicotine dependence. Arch Gen Psychiatr 65: 816-824.

Chen J, Xu Y, Zhang J, Liu Z, Xu C, Zhang K et al (2012). Genotypic association of the DAOA gene with resting-state brain activity in major depression. Mol Neurobiol 46: 361-373.

Cheon KA, Ryu YH, Kim JW, Cho DY (2005). The homozygosity for 10-repeat allele at dopamine transporter gene and dopamine transporter density in Korean children with attention deficit hyperactivity disorder: relating to treatment response to methylphenidate. Eu Neuropsychopharmacol 15: 95-101.

Chiang KP, Gerber AL, Sipe JC, Cravatt BF (2004). Reduced cellular expression and activity of the P129T mutant of human fatty acid amide hydrolase: evidence for a link between defects in the endocannabinoid system and problem drug use. Hum Mol Genet 13: $2113-2119$.

Domschke K, Dannlowski U, Hohoff C, Ohrmann P, Bauer J, Kugel $\mathrm{H}$ et al (2010). Neuropeptide Y (NPY) gene: Impact on emotional processing and treatment response in anxious depression. Eu Neuropsychopharmacol 20: 301-309.

Domschke K, Dannlowski U, Ohrmann P, Lawford B, Bauer J, Kugel $\mathrm{H}$ et al (2008). Cannabinoid receptor 1 (CNR1) gene: impact on antidepressant treatment response and emotion processing in major depression. Eu Neuropsychopharmacol 18: 751-759.

Drevets WC, Bogers W, Raichle ME (2002). Functional anatomical correlates of antidepressant drug treatment assessed using PET measures of regional glucose metabolism. Eu Neuropsychopharmacol 12: 527-544.

Durston S (2010). Imaging genetics in ADHD. NeuroImage 53: 832-838.

Edenberg HJ, Dick DM, Xuei X, Tian H, Almasy L, Bauer LO et al (2004). Variations in GABRA2, encoding the alpha 2 subunit of the $\mathrm{GABA}(\mathrm{A})$ receptor, are associated with alcohol dependence and with brain oscillations. Am J Hum Genet 74: 705-714.

Egan MF, Goldberg TE, Kolachana BS, Callicott JH, Mazzanti CM, Straub RE et al (2001). Effect of COMT Val108/158 Met genotype on frontal lobe function and risk for schizophrenia. PNAS USA 98: 6917-6922.

Egan MF, Kojima M, Callicott JH, Goldberg TE, Kolachana BS, Bertolino A et al (2003). The BDNF val66met polymorphism affects activity-dependent secretion of BDNF and human memory and hippocampal function. Cell 112: 257-269.

Filbey FM, Ray L, Smolen A, Claus ED, Audette A, Hutchison KE (2008). Differential neural response to alcohol priming and alcohol taste cues is associated with DRD4 VNTR and OPRM1 genotypes. Alcohol Clin Exp Res 32: 1113-1123.

Filbey FM, Schacht JP, Myers US, Chavez RS, Hutchison KE (2010). Individual and additive effects of the CNR1 and FAAH genes on brain response to marijuana cues. Neuropsychopharmacol 35: 967-975.

Franklin TR, Lohoff FW, Wang Z, Sciortino N, Harper D, Li Y et al (2009). DAT genotype modulates brain and behavioral responses elicited by cigarette cues. Neuropsychopharmacol 34: 717-728.

Franklin TR, Wang Z, Li Y, Suh JJ, Goldman M, Lohoff FW et al (2011). Dopamine transporter genotype modulation of neural responses to smoking cues: confirmation in a new cohort. Addict Biol 16: 308-322.

Fuke S, Suo S, Takahashi N, Koike H, Sasagawa N, Ishiura S (2001). The VNTR polymorphism of the human dopamine transporter (DAT1) gene affects gene expression. Pharmacogenom $J \mathbf{1}$ : 152-156.

Goldman D, Oroszi G, Ducci F (2005). The genetics of addictions: uncovering the genes. Nat Rev Genet 6: 521-532.

Hafeman DM, Chang KD, Garrett AS, Sanders EM, Phillips ML (2012). Effects of medication on neuroimaging findings in bipolar disorder: an updated review. Bipolar Disord 14: 375-410.

Hirvonen MM, Laakso A, Nagren K, Rinne JO, Pohjalainen T, Hietala J (2009). C957T polymorphism of dopamine D2 receptor gene affects striatal DRD2 in vivo availability by changing the receptor affinity. Synapse 63: 907-912.

Hong LE, Hodgkinson CA, Yang Y, Sampath H, Ross TJ, Buchholz $B$ et al (2010). A genetically modulated, intrinsic cingulate circuit supports human nicotine addiction. Proc Natl Acad Sci USA 107: 13509-13514.

Hutchison KE, Haughey H, Niculescu M, Schacht J, Kaiser A, Stitzel J et al (2008). The incentive salience of alcohol: translating the effects of genetic variant in CNR1. Arch Gen Psychiatr 65: 841-850.

Hutchison KE, LaChance H, Niaura R, Bryan A, Smolen A (2002). The DRD4 VNTR polymorphism influences reactivity to smoking cues. J Abnorm Psychol 111: 134-143.

Jacobsen LK, Pugh KR, Mencl WE, Gelernter J (2006). C957T polymorphism of the dopamine D2 receptor gene modulates the effect of nicotine on working memory performance and cortical processing efficiency. Psychopharmacology 188: 530-540.

Jamadar S, Powers NR, Meda SA, Calhoun VD, Gelernter J, Gruen JR et al (2013). Genetic influences of resting state fMRI activity in language-related brain regions in healthy controls and schizophrenia patients: a pilot study. Brain Imaging Behav 7: 15-27.

Janes AC, Smoller JW, David SP, Frederick BD, Haddad S, Basu A et al (2012). Association between CHRNA5 genetic variation at rs16969968 and brain reactivity to smoking images in nicotine dependent women. Drug Alcohol Depend 120: 7-13.

Jonsson EG, Nothen MM, Grunhage F, Farde L, Nakashima Y, Propping $\mathrm{P}$ et al (1999). Polymorphisms in the dopamine D2 receptor gene and their relationships to striatal dopamine receptor density of healthy volunteers. Mol Psychiatr 4: 290-296.

Kareken DA, Liang T, Wetherill L, Dzemidzic M, Bragulat V, Cox C et al (2010). A polymorphism in GABRA2 is associated with the medial frontal response to alcohol cues in an fMRI study. Alcohol Clin Exp Res 34: 2169-2178. 
Kessler RC, Chiu WT, Demler O, Merikangas KR, Walters EE (2005). Prevalence, severity, and comorbidity of 12-month DSM-IV disorders in the National Comorbidity Survey Replication. Arch Gen Psychiatr 62: 617-627.

Konarski JZ, McIntyre RS, Kennedy SH, Rafi-Tari S, Soczynska JK, Ketter TA (2008). Volumetric neuroimaging investigations in mood disorders: bipolar disorder versus major depressive disorder. Bipolar Disord 10: 1-37.

Kwaasteniet $\mathrm{BD}$, Ruhe E, Caan M, Rive M, Olabarriaga S, Groefsema $\mathrm{M}$ et al (2013). Relation between structural and functional connectivity in major depressive disorder. Biol Psychiatr 4: 40-47.

Kwok JB, Hallupp M, Loy CT, Chan DK, Woo J, Mellick GD et al (2005). GSK3B polymorphisms alter transcription and splicing in Parkinson's disease. Ann Neurol 58: 829-839.

Lerman C, Tyndale R, Patterson F, Wileyto EP, Shields PG, Pinto A et al (2006). Nicotine metabolite ratio predicts efficacy of transdermal nicotine for smoking cessation. Clin Pharm Therap 79: 600-608.

Lesch KP, Gutknecht L (2005). Pharmacogenetics of the serotonin transporter. Prog Neuropsychoph 29: 1062-1073.

Lui S, Wu Q, Qiu L, Yang X, Kuang W, Chan RC et al (2011). Resting-state functional connectivity in treatment-resistant depression. Am J Psychiatr 168: 642-648.

Loughead J, Wileyto EP, Valdez JN, Sanborn P, Tang K, Strasser AA et al (2009). Effect of abstinence challenge on brain function and cognition in smokers differs by COMT genotype. Mol Psychiatr 14: 820-826.

Mague SD, Blendy JA (2010). OPRM1 SNP (A118G): involvement in disease development, treatment response, and animal models. Drug Alcohol Depend 108: 172-182.

Mague SD, Isiegas C, Huang P, Liu-Chen LY, Lerman C, Blendy JA (2009). Mouse model of OPRM1 (A118G) polymorphism has sex-specific effects on drug-mediated behavior. Proc Natl Acad Sci USA 106: 10847-10852.

Malhotra AK, Zhang JP, Lencz T (2012). Pharmacogenetics in psychiatry: translating research into clinical practice. Mol Psychiatr 17: 760-769.

Mattay VS, Goldberg TE, Fera F, Hariri AR, Tessitore A, Egan MF et al (2003). Catechol O-methyltransferase val158-met genotype and individual variation in the brain response to amphetamine. Proc Natl Acad Sci USA 100: 6186-6191.

McClernon FJ, Hutchison KE, Rose JE, Kozink RV (2007). DRD4 VNTR polymorphism is associated with transient fMRI-BOLD responses to smoking cues. Psychopharmacology 194: 433-441.

McGuffin P, Rijsdijk F, Andrew M, Sham P, Katz R, Cardno A (2003). The heritability of bipolar affective disorder and the genetic relationship to unipolar depression. Arch Gen Psychiatr 60: 497-502.

Menon V (2011). Large-scale brain networks and psychopathology: a unifying triple network model. Trends Cogn Sci 15: 483-506.

Meyer-Lindenberg A, Nicodemus KK, Egan MF, Callicott JH, Mattay V, Weinberger DR (2008). False positives in imaging genetics. NeuroImage 40: 655-661.

Meyer-Lindenberg A, Weinberger DR (2006). Intermediate phenotypes and genetic mechanisms of psychiatric disorders. Nat Rev Neurosci 7: 818-827.

Michael AM, King MD, Ehrlich S, Pearlson G, White T, Holt DJ et al (2011). A data-driven investigation of gray matter-function correlations in schizophrenia during a working memory task. Front Hum Neurosci 5: 71.

Millan MJ, Agid Y, Brune M, Bullmore ET, Carter CS, Clayton NS et al (2012). Cognitive dysfunction in psychiatric disorders: characteristics, causes and the quest for improved therapy. Nat Rev Drug Discov 11: 141-168.

Pava MJ, Woodward JJ (2012). A review of the interactions between alcohol and the endocannabinoid system: implications for alcohol dependence and future directions for research. Alcohol 46: 185-204.

Plichta MM, Schwarz AJ, Grimm O, Morgen K, Mier D, Haddad L et al (2012). Test-retest reliability of evoked BOLD signals from a cognitive-emotive fMRI test battery. NeuroImage 60: $1746-1758$.

Ramchandani VA, Umhau J, Pavon FJ, Ruiz-Velasco V, Margas W, Sun $\mathrm{H}$ et al (2011). A genetic determinant of the striatal dopamine response to alcohol in men. Mol Psychiatr 16: 809-817.

Ray LA, Barr CS, Blendy JA, Oslin D, Goldman D, Anton RF (2012). The role of the Asn40Asp polymorphism of the mu-opioid receptor gene (OPRM1) on alcoholism etiology and treatment: a critical review. Alcohol Clin Exp Res 36: 385-394.

Ray R, Loughead J, Wang Z, Detre J, Yang E, Gur R et al (2008). Neuroimaging, genetics and the treatment of nicotine addiction. Behav Brain Res 193: 159-169.

Ray R, Ruparel K, Newberg A, Wileyto EP, Loughead JW, Divgi C et al (2011). Human Mu-opioid Receptor (OPRM1 A118G) polymorphism is associated with brain mu-opioid receptor binding potential in smokers. Proc Natl Acad Sci USA 108: 9268-9273.

Rohde LA, Roman T, Szobot C, Cunha RD, Hutz MH, Biederman J (2003). Dopamine transporter gene, response to methylphenidate and cerebral blood flow in attention-deficit/hyperactivity disorder: a pilot study. Synapse 48: 87-89.

Rosenblau G, Sterzer P, Stoy M, Park S, Friedel E, Heinz A et al (2012). Functional neuroanatomy of emotion processing in major depressive disorder is altered after successful antidepressant therapy. J Psychopharmacol 26: 1424-1433.

Roussos P, Giakoumaki SG, Bitsios P (2009). Tolcapone effects on gating, working memory, and mood interact with the synonymous catechol-O-methyltransferase $\mathrm{rs} 4818 \mathrm{c} / \mathrm{g}$ polymorphism. Biol Psychiatr 66: 997-1004.

Ruhe HG, Ooteman W, Booij J, Michel MC, Moeton M, Baas F et al (2009). Serotonin transporter gene promoter polymorphisms modify the association between paroxetine serotonin transporter occupancy and clinical response in major depressive disorder. Pharmacogenet Genom 19: 67-76.

Savitz J, Nugent AC, Bogers W, Liu A, Sills R, Luckenbaugh DA et al (2010). Amygdala volume in depressed patients with bipolar disorder assessed using high resolution 3T MRI: the impact of medication. NeuroImage 49: 2966-2976.

Schacht JP, Anton RF, Voronin KE, Randall PK, Li X, Henderson S et al (2013). Interacting effects of naltrexone and OPRM1 and DAT1 variation on the neural response to alcohol cues. Neuropsychopharmacol 38: 414-422.

Schnoll RA, Patterson F, Wileyto EP, Tyndale RF, Benowitz N, Lerman C (2009). Nicotine metabolic rate predicts successful smoking cessation with transdermal nicotine: a validation study. Pharm Biochem Be 92: 6-11.

Sinha R, Li CS (2007). Imaging stress- and cue-induced drug and alcohol craving: association with relapse and clinical implications. Drug Alcohol Rev 26: 25-31.

Sommer WH, Lidstrom J, Sun H, Passer D, Eskay R, Parker SC et al (2010). Human NPY promoter variation rs16147:T $>C$ as a moderator of prefrontal NPY gene expression and negative affect. Hum Mutat 31: E1594-E1608.

Szobot CM, Roman T, Hutz MH, Genro JP, Shih MC, Hoexter MQ et al (2011). Molecular imaging genetics of methylphenidate response in ADHD and substance use comorbidity. Synapse 65: 154-159.

Tan HY, Chen AG, Kolachana B, Apud JA, Mattay VS, Callicott JH et al (2012). Effective connectivity of AKT1-mediated dopaminergic working memory networks and pharmacogenetics of anti-dopaminergic treatment. Brain 135(Pt 5): 1436-1445.

Tang DW, Hello B, Mroziewicz M, Fellows LK, Tyndale RF, Dagher A (2012). Genetic variation in CYP2A6 predicts neural reactivity to smoking cues as measured using fMRI. NeuroImage 60: 2136-2143. 
Theberge J (2008). Perfusion magnetic resonance imaging in psychiatry. Top Magn Reson Imaging 19: 111-130.

Tost H, Bilek E, Meyer-Lindenberg A (2012). Brain connectivity in psychiatric imaging genetics. NeuroImage 62: 2250-2260.

Tyndale RF, Payne JI, Gerber AL, Sipe JC (2007). The fatty acid amide hydrolase C385A (P129T) missense variant in cannabis users: studies of drug use and dependence in Caucasians. Am J Med Genet B 144B: 660-666.

van Belzen MJ, Heutink P (2006). Genetic analysis of psychiatric disorders in humans. Genes Brain Behav 5(Suppl 2): 25-33.

Wang Z, Ray R, Faith M, Tang K, Wileyto EP, Detre JA et al (2008). Nicotine abstinence-induced cerebral blood flow changes by genotype. Neurosci Lett 438: 275-280.

Weerts EM, McCaul ME, Kuwabara H, Yang X, Xu X, Dannals RF et al (2012). Influence of OPRM1 Asn40Asp variant (A118G) on
[11C]carfentanil binding potential: preliminary findings in human subjects. Int J Neuropsychopharmacol 16: 47-53.

Wetherill RR, Jagannathan K, Lohoff FW, Ehrman R, O'Brien CP, Childress AR et al (2012). Neural correlates of attentional bias for smoking cues: modulation by variance in the dopamine transporter gene. Addict Biol; e-pub ahead of print. doi:10.1111/ j.1369-1600.2012.00507.x.

Wilcox CE, Claus ED, Blaine SK, Morgan M, Hutchison KE (2013). Genetic variation in the alpha synuclein gene (SNCA) is associated with BOLD response to alcohol cues. J Studies Alcohol Drugs 74: 233-244.

Zhang PW, Ishiguro H, Ohtsuki T, Hess J, Carillo F, Walther D et al (2004). Human cannabinoid receptor 1: $5^{\prime}$ exons, candidate regulatory regions, polymorphisms, haplotypes and association with polysubstance abuse. Mol Psychiatr 9: 916-931. 